\title{
APLICAÇÃO DO MÉTODO FRETE GRÁTIS EM UMA LOJA VIRTUAL EM CONJUNTO A ANÁLISES DE DADOS E COMPARATIVOS ATRAVÉS DO SOFTWARE POWER BI
}

\author{
THE APPLICATION OF THE FREE SHIPPING METHOD IN A VIRTUAL STORE TOGETHER WITH DATA \\ ANALYSIS AND COMPARATIVES THROUGH THE POWER BI SOFTWARE
}

\author{
Felipe Lorenzeto de Souza ${ }^{1 *}$, Ritler Barbosa Ramos $2^{2 *}$, Tiago Bittencourt Nazaré $3^{3}$, Sanderson Rocha \\ de Abreu $4^{4}$, Felipe Xavier Ribeiro Pacifico $5^{5}$
}

\begin{abstract}
${ }^{1}$ Graduando em Engenharia de Produção pela Faculdades Integradas de Cataguases FIC-UNIS, Cataguases, Minas Gerais, Brasil, felipe.souza@alunos.unis.edu.br.

${ }^{2}$ Graduando em Engenharia de Produção pela Faculdades Integradas de Cataguases FIC-UNIS, Cataguases, Minas Gerais, Brasil, ritler.ramos@alunos.unis.edu.br.

${ }^{3}$ Orientador: Professor titular das Faculdades Integradas de Cataguases FIC-UNIS. Graduado em Sistemas de Informação pelo Instituto Doctum de Educação e Tecnologia e Especializado em Redes de Comunicação pela Universidade Gama Filho. Mestre em Gestão de Sistemas de Engenharia pela Universidade Católica de Petrópolis, Cataguases, Minas Gerais, Brasil, tiago.nazare@professor.unis.edu.br, ${ }^{4}$ Orientador: Coordenador e Professor dos cursos de Engenharia de Produção e Engenharia Elétrica da Faculdades Integradas de Cataguases FIC-UNIS. Mestre em Engenharia Elétrica pela Universidade Estadual de Campinas - UNICAMP. Graduado em Engenharia de Produção pelas Faculdades Integradas de Cataguases- FIC e Técnico em Eletrotécnica pela Universidade Federal de Juiz de Fora - UFJF, Cataguases, Minas Gerais, Brasil, sanderson.abreu@professor.unis.edu.br.

${ }^{5}$ Orientador: Professor titular das Faculdades Integradas de Cataguases FIC-UNIS. Graduado em Engenharia de Produção e Engenharia Elétrica, Especialista em Engenharia Elétrica e MBA em Gestão Estratégica de Pessoas e Gestão de Projetos,
\end{abstract} felipe.xavier@professor.unis.edu.br.

* Autores da correspondência.

\section{Resumo}

O presente artigo tem por objetivo o estudo realizado através da análise de dados com o auxílio do software Power BI em uma loja virtual de instrumentos musicais. Para a elaboração desse contexto foram exportados os dados através da plataforma "ADM" da loja virtual, onde foram coletadas as informações do cadastro dos clientes, históricos de pedidos, histórico de vendas, carrinhos abandonados e finalizados. Foi aplicada uma metodologia de "Frete Grátis" baseada em dois estudos de caso, o primeiro estudo relaciona "Abandono de Carrinho em um E-Commerce" e para a certificação da teoria, utilizou-se também a correlação com a pesquisa "A Influência do Frete no E-Commerce Brasileiro". Ambas as pesquisas citam que para o cliente o frete é o ponto mais critico ao se finalizar ou não uma compra em lojas online, e que apontam como atrativo a modalidade "Frete Grátis". Com os resultados obtidos após a aplicação do método por três meses, foram realizadas novas análises e comparativos a fim de confrontar a eficiência dos estudos de caso versus a prática. O resultado apontou que a modalidade aumentou a média trimestral de vendas em $57,8 \%$ contemplando 100 novas vendas a mais que o período anterior, e diminuiu em $34,2 \%$ o abandono de carrinhos que em quantitativo representam 64 carrinhos. Deste modo pode-se comprovar que o "Frete Grátis" é eficaz para alavancagem de vendas e queda no abandono de carrinhos. Palavras chaves: Loja Virtual, Coleta de Dados, Power BI, E-commerce, Abandono de Carrinho e Frete Grátis.

\footnotetext{
Abstract

This article aims at the study carried out through data analysis with the aid of Power BI software in a virtual musical instrument store. For the elaboration of this context, the data were exported through the "ADM" platform of the virtual store, where the information of the customer register, order history, sales history, abandoned and finished carts were collected. A methodology of "Free Shipping" was applied based on two case studies, the first study relates "Abandonment of Cart in an E-Commerce" and for theory certification, it was also used the correlation with the research "The Influence of Shipping in Brazilian E-Commerce". Both surveys mention that for the customer, shipping is the most critical point when completing or not a purchase in online stores, and that they point out as attractive the "Free Shipping" modality. With the results obtained after applying the method for three months, new analyzes and comparisons were carried out in order to confront the efficiency of the case studies versus the practice. The result pointed out that the modality increased the quarterly average of sales by $57.8 \%$, contemplating 100 new sales more than the previous period, and decreased by $34.2 \%$ the abandonment of carts which, in quantitative terms, represent 64 carts. In this way, it can be proven that "Free Shipping" is an effective sales leverage and drop in cart abandonment.
} 
Keywords: Online Store, Data Collection, Power BI, Ecommerce, Cart Abandonment and Free Shipping.

\section{INTRODUÇÃO}

Com o intuito de se destacar no mercado digital e alavancar suas vendas com ações estratégicas, as empresas que atuam no E-commerce buscam conhecer cada dia mais os hábitos, costumes e práticas de seus clientes. Além de possibilitar o aprimoramento das ações e também nortear as tomadas de decisões, as pesquisas sobre os hábitos, costumes e práticas de seus clientes podem facilitar a identificação do produto ou serviço específico categorizando seu público alvo.

Como define Kauzaqui (2019), as empresas digitais e os varejos tradicionais estão implantando uma forma mais completa e abrangente para atender as vendas online, definindo desta forma o conceito de Marketplace digital. Para Bertholdo (2019), E-Commerce e suas plataformas digitais são acessíveis através da interação de smartphones, computadores e ou tablets por meio de redes de internet com o intuito de negociações online.

Segundo Eugênio (2013), o ponto primordial para potencializar as vendas do e-commerce é entender e melhorar os custos dos fretes e efetuar as entregas de produtos dentro do prazo estabelecido. Para isso é necessário buscar e/ou criar estratégias eficientes a fim de proporcionar menores e melhores opções de frete, ou até mesmo a possibilidade de oferecer o frete gratuito.

Desse modo o presente artigo tem como finalidade demonstrar a modelagem dos dados extraídos do sistema "ADM" da Loja Virtual, criando-se gráficos e demonstrativos obtidos através da ferramenta Power BI. Além disso será apresentado a aplicabilidade da metodologia "Frete Grátis" obtida através de estudo de caso, confrontando ao final a eficiência da teoria versus prática.

\section{REFERENCIAL TEÓRICO}

Para se alcançar os resultados sobre a aplicação da pesquisa, é necessário conceitos práticos e teóricos para embasamento das ferramentas e metodologias aplicadas. Nesse modelo serão abordados fundamentos essenciais para o desenvolvimento estrutural e aplicação prática do trabalho.

\subsection{E-commerce}

As organizações vivem hoje em um ambiente extremamente competitivo e dinâmico, onde para se manter no mercado é necessária uma busca constante por melhoria e qualidade dos produtos ou serviços oferecidos. Para as empresas de e-commerce ter esse diferencial tem se tornado um ponto crucial para sua sobrevivência no mercado.

Segundo Nascimento (2009), o e-commerce como é conhecido no Brasil, iniciou-se na década dos anos 90, quando foram criados os primeiros sites na internet com objetivo de realizar transações comerciais. Ainda de acordo com Nascimento (2009), como todo início de um novo conceito, as transações com lojas online ainda eram bem pequenas, mas com a mudança decorrentes do mercado mundial, não demorou para que esse novo conceito de compra e venda se tornasse o maior e o mais popular método de produtos e serviços.

Para Nuernberg (2010), o e-commerce veio para facilitar a vida dos consumidores e maximizar os lucros das empresas. Atualmente, não tratar as vendas online como uma prioridade é se colocar inferior perante aos concorrentes, uma vez que o mercado se encontra cada vez mais acirrado com a entrada de micros e pequenas empresas. 
Conforme Laudon e Traver (2017), o e-commerce corresponde ao uso da Internet, aplicativos e/ou navegadores, executados em dispositivos móveis ou desktop para a realização de apresentação de produtos e serviços a fim de facilitar negociações, gerando assim dados valiosos para as organizações. Logo, de forma mais pontual, o comércio eletrônico pode ser classificado como transações realizadas digitalmente de forma a interligar organizações e clientes.

\title{
2.2 Análise de dados
}

Potter (2018) conceitua a análise de dados como:

\begin{abstract}
Analisar os dados de forma fundamentada e efetiva se torna um desafio tanto para pequenas, médias quanto grandes empresas. O desenvolvimento real acontece quando há acompanhamento de indicadores e reflete por toda a estrutura de valores e a estratégia competitiva da organização. Com o aparecimento de novas metodologias e softwares essenciais para apoiar a tomada de decisão através das análises. O uso dessas metodologias valia ainda mais a importância para a sustentabilidade das empresas de negócios. (POTTER 2018 apud, MARQUES, TESTONY e RUDY,2018)
\end{abstract}

Conforme citado por Haider (2015) uma organização pode conter uma grande massa de dados gerados por diversas origens como produção, clientes, vendas, mídias sociais entre outros, porém os mesmos não possuem valor em sua forma bruta, criando assim a necessidade da utilização de ferramentas que permitem modelar, interpretar e transformar os dados em informações relevantes para tomadas de decisões.

\section{METODOLOGIA}

Para o presente estudo foram realizadas pesquisas bibliográficas em livros, revistas, artigos científicos e sites acadêmicos. A pesquisa foi desenvolvida em um Loja de Instrumentos Musicais de modo quantitativo, descritivo e com base em dois estudos de caso, um elaborado por Souza (2019) cujo o tema abordado "Abandono de carrinho em e-commerce no Brasil", e o segundo por Junior e Rocha (2021) que relata "A influência do frete no e-commerce Brasileiro", ambos os estudos possuem como similaridade a utilização da pesquisa de satisfação e a correspondência dos resultados obtidos referente à metodologia de "Frete Grátis" em um e-commerce.

Para realizar o processamento e integração dos dados foi utilizado o método denominado ETL, abreviatura para o termo das três etapas que são compostas por Extract, Transform e Load (Extração, transformação e carregamento) de data-warehouse. Para Elmasri e Navathe (2011), um data warehouse é diferente de um banco de dados tradicional em sua estrutura, funcionamento e finalidade pois está interligado ao sistema de gestão da plataforma.

Para a elaboração prática foram coletadas informações através da plataforma "ADM" da loja virtual, e com o auxílio da ferramenta Power BI foram realizados análises e comparativos de cenários após três meses de aplicabilidade para confrontar teoria com a prática, demonstrando de forma objetiva os resultados obtidos através de gráficos e análises estatísticas.

\subsection{A loja virtual}

Há oito anos no mercado, a Loja Virtual de Instrumentos Musicais tem como seu principal objetivo a venda B2C (Business-to-Consumer) interligada diretamente aos consumidores finais. Sua distribuição é feita em todo o território nacional, sua logística de entrega é exclusivamente realizada 
por transportadoras e pelos serviços dos correios.

Com uma ampla concorrência em um ambiente extremamente competitivo e dinâmico, a Loja de Instrumentos Musicais em estudo, busca constantemente por novas estratégias para obter melhores resultados.

\subsection{Coleta de Dados}

O desenvolvimento do estudo foi baseado nos dados coletados do sistema de gerenciamento da Loja Virtual de Instrumentos Musicais através de sua plataforma "ADM". Os dados foram coletados em formato de planilhas e importados para a ferramenta Power BI conforme apresenta a imagem 1.

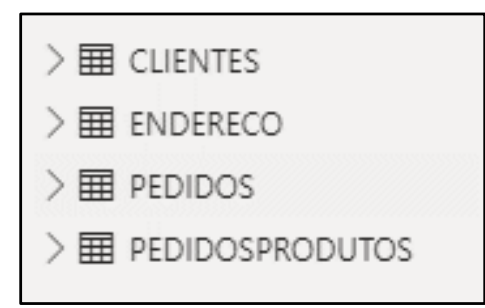

Fonte: Próprios autores (2021).

Imagem 1 - Tabelas geradas e importadas para o Power BI.

A Imagem acima destaca as quatro tabelas importadas para a ferramenta Power $\mathrm{BI}$, a base de dados CLIENTE descreve as informações pessoais de cada cliente cadastrado; A de ENDEREÇO, contemplam os dados de endereço dos clientes; Para PEDIDOS, são os dados de carrinhos criados, finalizados e abandonados; E a base de PEDIDO PRODUTOS é o detalhamento dos produtos oferecidos pela loja.

Com a ferramenta é possível realizar análises apuradas, com visibilidade abrangente e de fácil entendimento através de gráficos e tabelas através da modelação de dados. Um dos pontos mais atrativos do Power BI é tornar possível análises com a interligação de bancos de dados, ou seja, criar e visualizar novos parâmetros com correlações conforme apresenta a imagem 2. 


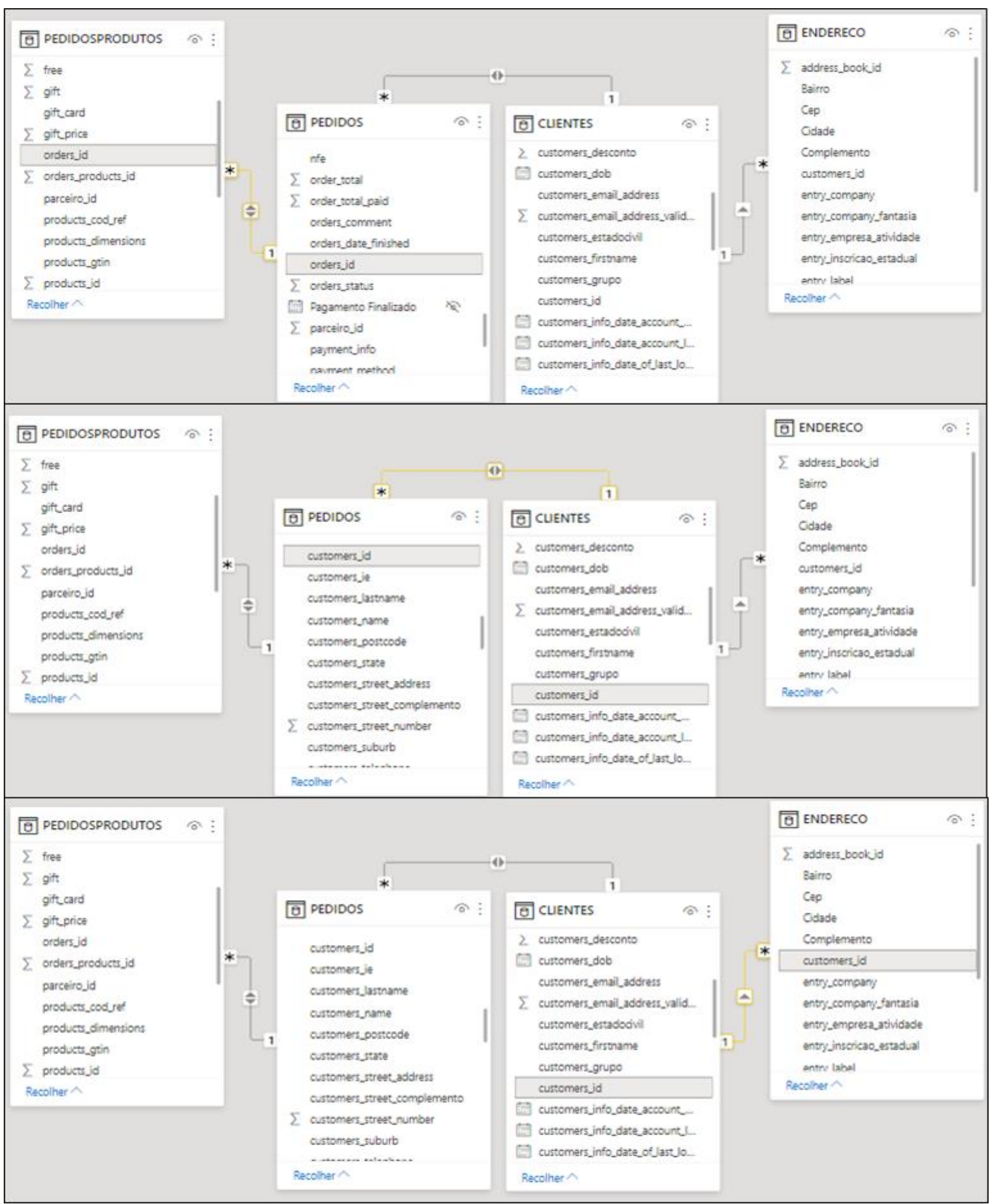

Fonte: Próprios autores (2021).

Imagem 2 - Correlações entre itens e tabelas no Power BI.

A Imagem 2 retrata uma das etapas mais importantes na modelação de dados na ferramenta Power Bl, a correlação entre tabelas, que permite interligar os diferentes bancos de dados por alguma coluna que se relacione, a fim de possibilitar maior abrangência nas análises futuras em gráficos e interfaces interativas. 


\subsection{Análise e modelação no Power BI}

Este estudo se baseou no método de análise de dados utilizando a ferramenta Power Bl, que teve como principal objetivo organizar, analisar e comparar os resultados. As análises dos dados pela ferramenta, foram subdivididas em duas partes.

Primeiramente foram analisadas informações interligadas ao cadastro como estado de origem, gênero, faixa etária, tipo de conta e como conheceu o site. Em seguida foram analisadas informações direcionadas a vendas, tais como carrinhos de compra finalizados, abandonados e também dados interligados ao cadastro como público por idade que mais comprou, como conheceu e por regiões.

Para tanto, foram desenvolvidos gráficos e demonstrativos, por onde foram centralizados e organizados todos os dados coletados de forma a modelar resultados precisos baseados em médias estatísticas, que serviram como comparativos e indicadores.

\subsection{Gráficos e Análises dos dados}

A Partir dos bancos de dados obtidos pela plataforma "ADM" e modelados no Power Bl, foram gerados diversos gráficos e cenários para identificação dos resultados da loja. Os critérios utilizados para a montagem de cada gráfico encontram-se no Apêndice I.

\subsubsection{Análise Cadastral Ampliada}

Com o intuito de visualizar, identificar e conhecer os clientes da Loja Virtual, foi criado duas abas de gráficos e indicadores interligadas a base cadastral. Na Aba inicial buscou-se uma análise resumida, conforme informa a imagem 3.

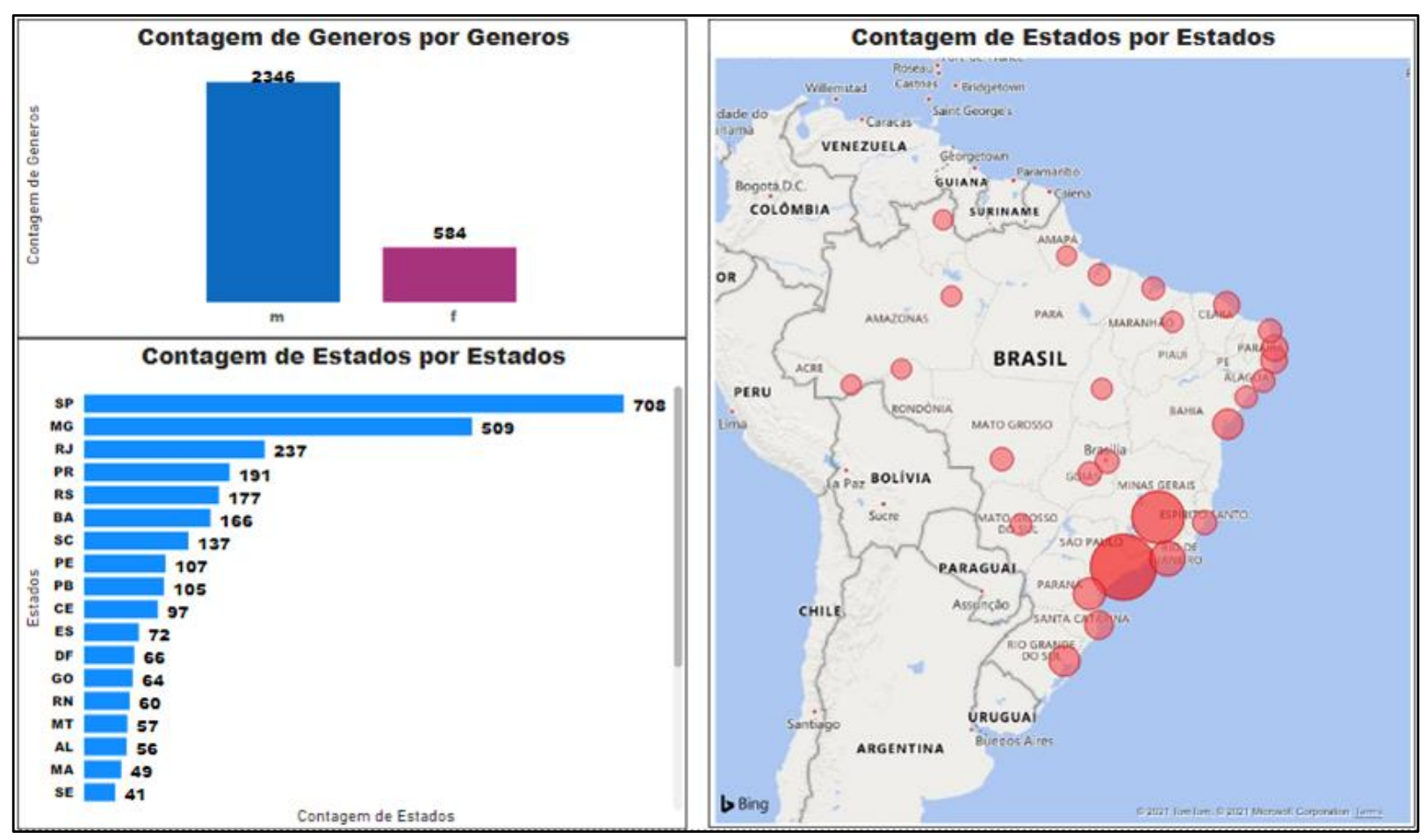

Fonte: Próprios autores (2021).

Imagem 3 - Análise Aba 1 base Cadastral. 
SOUZA, Felipe Lorenzeto; RAMOS, Ritler Barbosa; NAZARÉ, Tiago Bittencourt.

A Imagem 3 relata a primeira aba de análise do software Power Bl, com gráficos identificando o as contas cadastradas por gênero, quantitativo por estado e sua demonstração no gráfico geográfico. Buscando uma análise ampla direcionada aos cadastros, foi gerado novos gráficos e modelos como mostra a imagem 4.

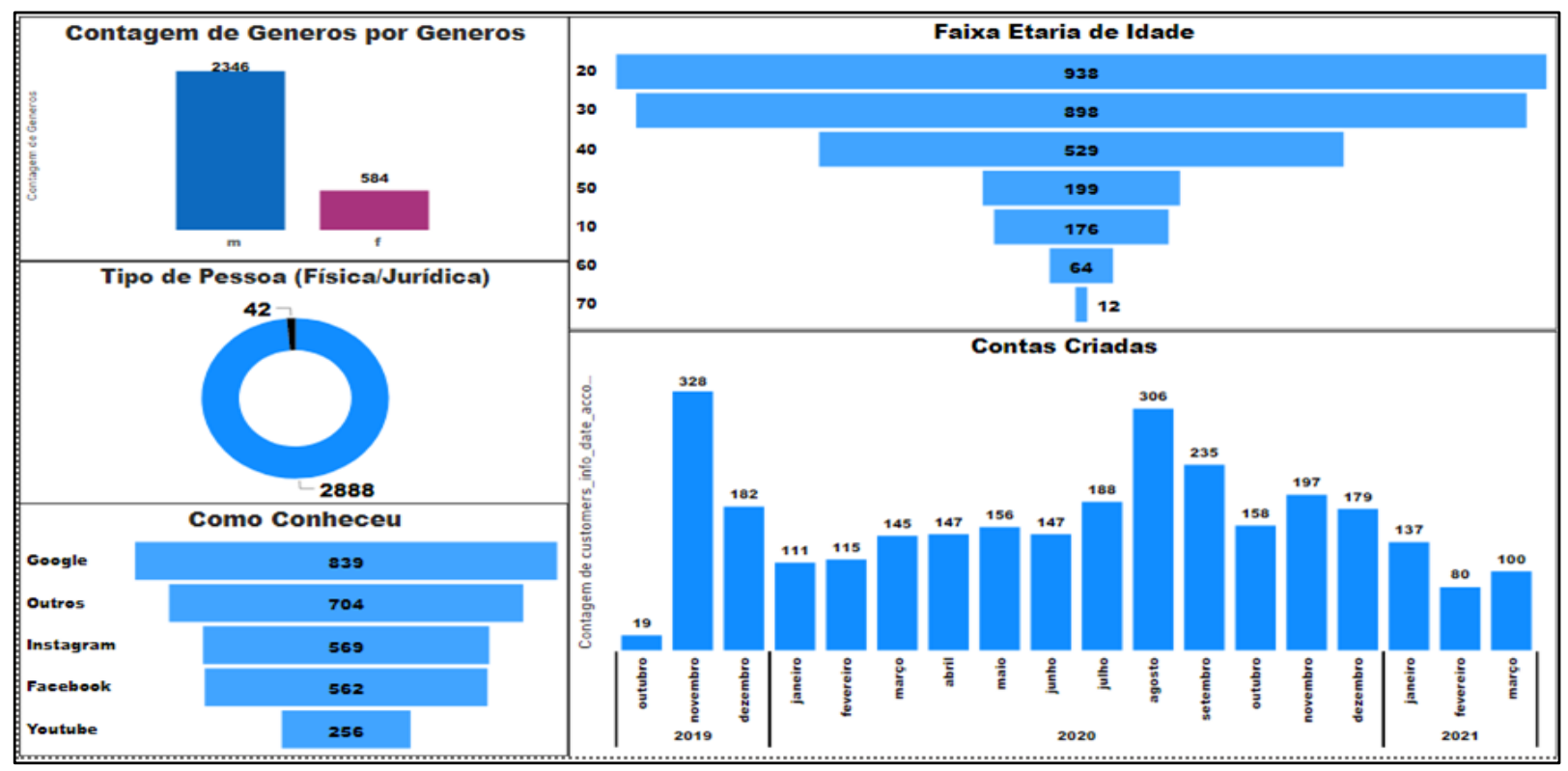

Fonte: Próprios autores (2021).

Imagem 4 - Análise Aba 2 Base Cadastral Ampliada.

De acordo com a imagem 4, na aba 2 é possível visualizar gráficos ampliando os itens da Base Cadastral, podendo neste modelo identificar o Tipo de Cadastramento como físico ou jurídico, como o cliente conheceu o site, faixa etária de idade aglutinada em casas decimais e o quantitativo de contas criadas mensalmente.

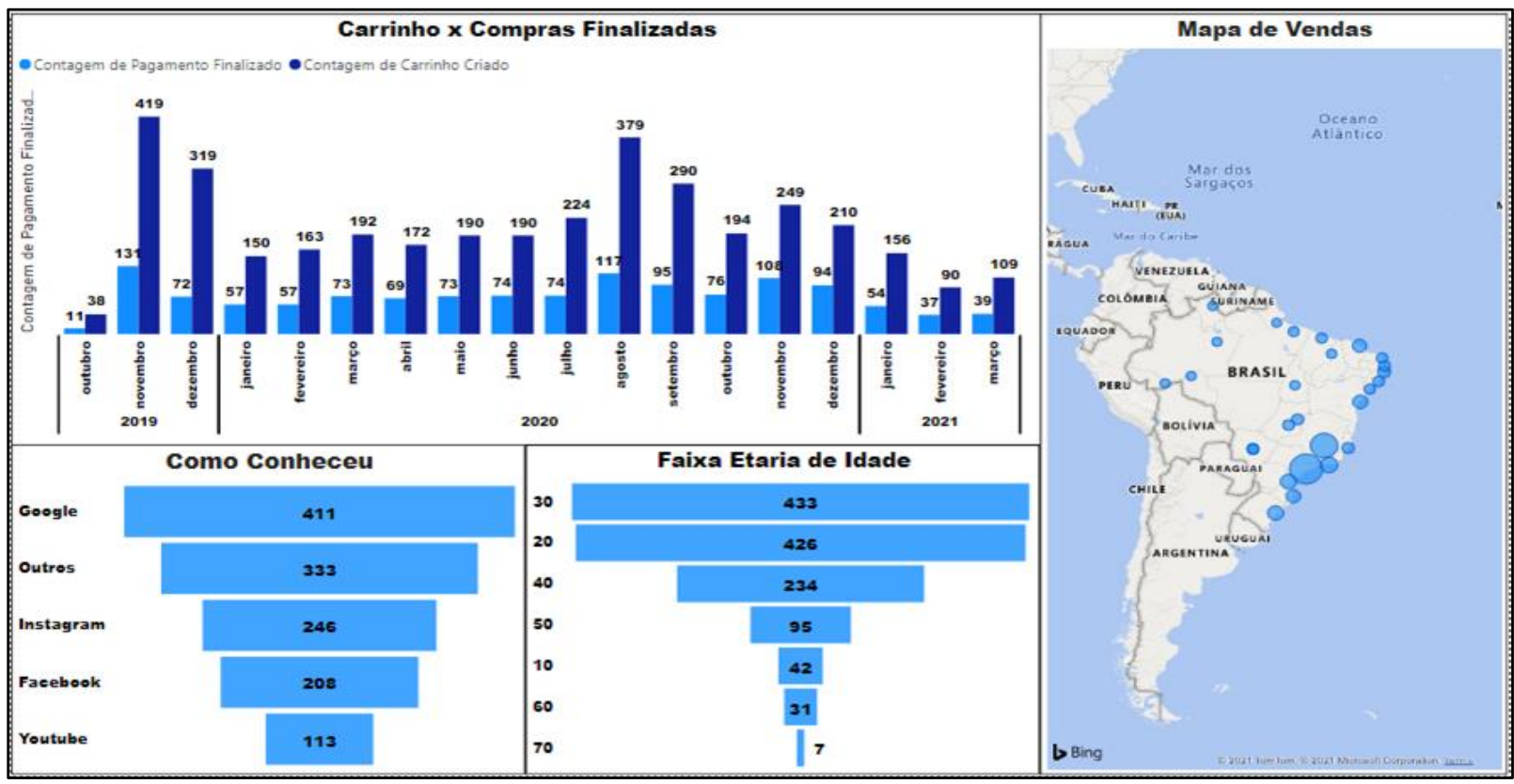

Fonte: Próprios autores (2021).

Imagem 5 - Análise Aba 3 Base Cadastral Vendas 
A Aba 3 em concordância com a imagem 5, retrata o cenário de vendas da loja online, podendo neste contexto visualizar os dados baseado nas vendas correlacionados a base cadastral, como o mapa geográfico das vendas, como conheceu a loja baseado nas vendas, faixa etária de idade de quem criou os carrinhos e Carrinhos Criados versus Carrinhos Finalizados.

Ainda sobre a Imagem 5, foi possível visualizar o quantitativo elevado de Carrinhos Criados e não finalizados, tornado este indicador um ponto de atenção e oportunidade de melhoria para a Loja Virtual. Por tanto, foi priorizado como objetivo de estudo, práticas que impactassem a redução de Carrinhos Abandonados, buscando agregar eficácia nas vendas.

\subsection{Estudo de Caso}

A escolha do estudo de caso, baseou-se em dois artigos, o primeiro desenvolvido por Souza (2019) cujo tema aborda sobre Abandono de Carrinho em E-Commerce no Brasil denominado como "Caso INT" e o segundo por Júnior e Rocha (2021) enfatizando "A Influência do Frete no ECommerce Brasileiro".

Para Souza (2019), através de uma pesquisa realizada pela autora, foram entrevistados 52 clientes decorrentes de venda via WhatsApp, onde mais da metade relataram que o frete é um limitador das compras on-line, e que o frete grátis os faria mudar de ideia.

No mesmo contexto, uma pesquisa realizada por Júnior e Rocha (2021) através de uma enquete pelo Instagram, teve como tema base o impacto custo do frete no e-commerce brasileiro. No total 518 participantes responderam a enquete, e o resultado obtido também demonstrou o grande interesse dos consumidores por produtos com frete grátis.

Baseando-se nas pesquisas elaboradas pelos autores e considerando o grande interesse em "Frete Grátis" pelos consumidores, foi enfatizado uma possível estratégia a ser utilizada na Loja de Instrumentos Musicais, podendo assim confrontar teoria com a prática.

\section{RESULTADO E DISCUSSÃO}

Após a aplicação do método "Frete Grátis" durante 3 meses, foi realizado o comparativo entre os bancos de dados gerados pelo software Power $B /$ tendo como contexto a análise dos gráficos gerados pela ferramenta, a fim de correlacionar os resultados obtidos com as teorias em questão, como detalha a tabela 1.

Tabela 1 - Análise Comparativa de Carrinhos Abandonados.

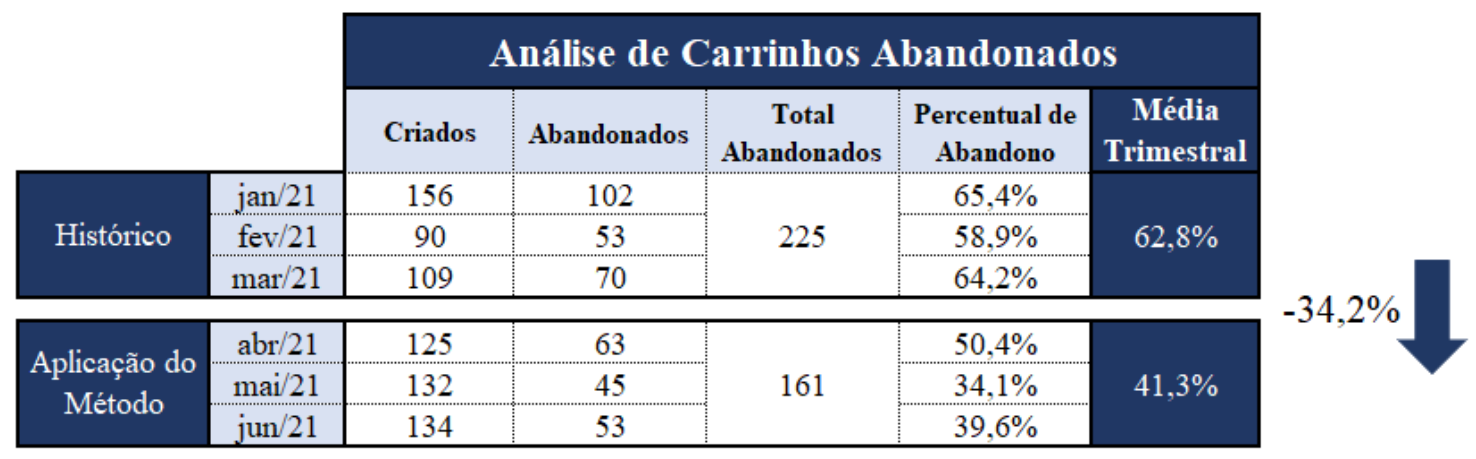

Fonte: Próprios autores (2021). 
Como demonstrado na tabela 1, foram totalizados 225 carrinhos abandonados no histórico trimestral, após a aplicação do método um total de 161, resultando em uma queda de 64 Carrinhos Abandonados e uma redução de 34,2\% na média trimestral.

Tabela 2 - Análise Histórica de Carrinhos x Compras.

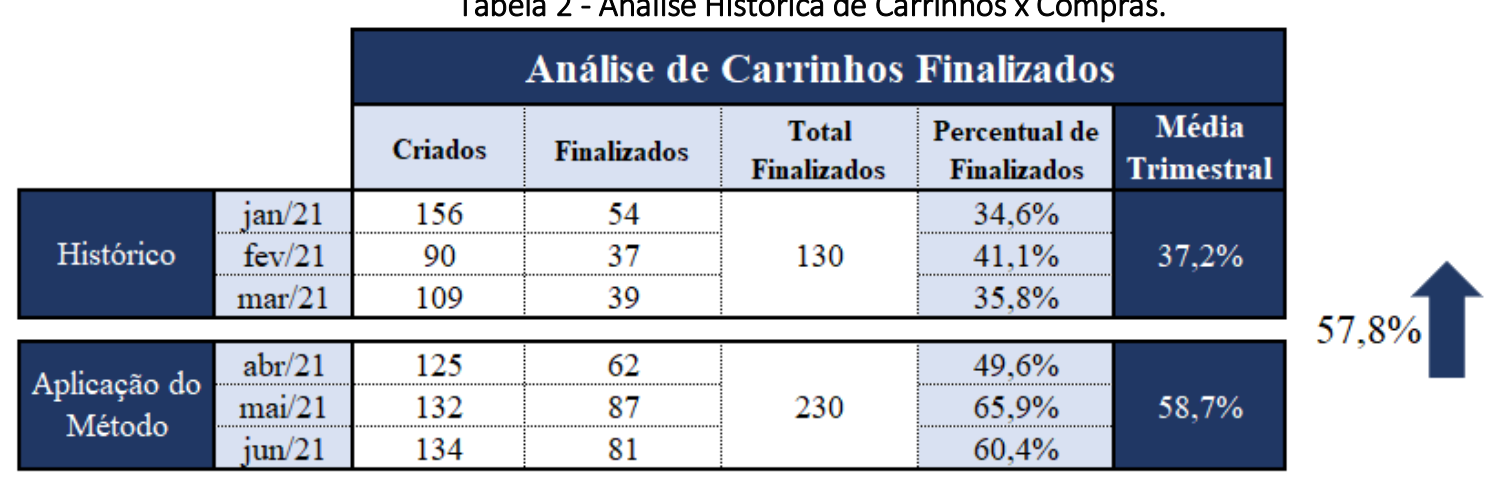

Fonte: Próprios autores (2021).

Usando o mesmo critério de análise da tabela anterior, identificamos que o anúncio de "Frete Grátis" demonstrou ser mais atrativo para vendas da loja virtual, impulsionando assim seus resultados de vendas finalizadas. No $1^{\circ}$ trimestre foram registradas 130 finalizações de carrinho e no $2^{\circ}$ trimestre 230, contemplando um aumento de 100 novas vendas entre os períodos e um crescimento de 57,8\% nos carinhos finalizados.

Assim como demonstrado nas tabelas acima, podemos observar um aumento significativo entre o cenário anterior e o posterior a aplicação, com tudo a metodologia Frete Grátis demonstrou ser muito promissora, uma vez que a mesma promoveu um impacto notório e positivo referente aos Carrinhos Abandonados e Carrinhos Finalizados.

De acordo com a pesquisa realizada por Souza (2019), mais da metade dos participantes disseram que o frete seria o maior limitador e que o "FRETE GRÀTIS" os faria mudar de ideia. Dentro deste mesmo contexto, comparando os resultados obtidos, podemos observar que o uso da metodologia aplicada está correlacionado positivamente com a pesquisa relacionada pelo autor, e isso explica o fato dos aumentos das vendas e também a diminuição dos abandonos de Carrinhos nos últimos 3 meses do método aplicado.

Como citado por Júnior e Rocha (2021) em sua pesquisa, o frete não é meramente apenas um detalhe dentro da loja virtual e sim uma grande ferramenta na decisão do consumidor. Assim com os resultados práticos obtidos nessa aplicação, sua pesquisa também conclui que o Frete Grátis é de extrema importância, e que além de atrair a atenção dos compradores, torna-se para o E-Commerce uma estratégia a fim de maximizar o faturamento, com tudo também significa investir no marketing da Loja Virtual.

\section{CONSIDERAÇÕES FINAIS}

O artigo teve como objetivo a análise de dados de uma loja virtual de instrumentos musicais através do software Power $B I$, onde foi identificado um número elevado de abandono de carrinhos. 
Nesse contexto foram realizadas pesquisas bibliográficas em livros, revistas, artigos científicos e sites acadêmicos. Através dessas consultas foi identificado um estudo de caso realizado por Sousa (2019), no qual a autora realizou uma pesquisa de satisfação com alguns clientes referente a motivos pelos quais abandonaram o carrinho de compra. O resultado da pesquisa apontou que mais da metade dos participantes, disseram que o valor do frete seria o maior limitador da compra e que o frete grátis os faria mudar de ideia.

Ainda como afirmação para a teoria citada, foi correlacionar os resultados obtidos por Junior e Rocha (2021) que de mesmo modo através de uma pesquisa de satisfação, obteve como resultados o grande interesse dos compradores a produtos com o Frete Grátis.

Após a aplicação da metodologia em confronto com o histórico de vendas em estudo, obteve como resultado que a teoria foi comprovada com base na aplicação do estudo de caso. Neste contexto foi evidenciado uma queda de $34,2 \%$ nos abandonos de carrinho e um aumento significativo de $57,8 \%$ nas vendas. Contudo se conclui que a modalidade "Frete Grátis" é eficiente e eficaz, gerando assim resultados satisfatórios para a empresa que a utiliza.

\section{REFERÊNCIA BIBLIOGRÁFICAS}

BERTHOLDO. E-commerce - o que é, quais os tipos e muito mais, 2019. Disponível em: https://www.bertholdo.com.br/blog/o-que-e-e-commerce/. EUGÊNIO, Márcio. Seis dicas sobre formas de entrega para e-commerce, 2013. Disponível em: https://www.ecommercebrasil.com.br/artigos/seis-dicas-formas-entrega-commerce/>. Acesso em 18 abril. 2021.

HAIDER, M. Getting Started with Data Science: Making Sense of Data with Analytics. Indianápolis: IBM Press, 2015.

KAUZAQUI, Edmir; HADDAD, Helder; MARANGONI, Matheus M. Gestão de Marketing 4.0 - Casos, Modelos e Ferramentas. São Paulo: Atlas, 2019

NASCIMENTO, André Ribeiro do; SILVA, Bruna Ferreira da; SANTOS, Gisele Gomes dos. E-commerce: 0 Melhor Caminho no Mercado Atual / Marília, SP: [s.n.], 2009. 70 f.

NUERNBERG, Júlio C. O Futuro do Comércio Eletrônico. Revista Olhar Científico - Faculdades Associadas de Ariquemes, Roraima: 2010. Disponível em:

http://www.olharcientifico.kinghost.net/index.php/olhar/article/view/54/38>. Acesso em 18 abril. 2021.

Potter 1985 apud Marques e Testoni e Rudy 2018. DOS DADOS AO CONHECIMENTO: BUSINESS INTELLIGENCE COMO FERRAMENTA PARA APOIO À TOMADA DE DECISÃO 1. Disciplinarum Scientia. v. 13 2018

SANTOS JUNIOR, Jonas Monteiro dos; ROCHA, Marcio Dourado. A Influência do Frete no E-Commerce Brasileiro. Disponível em: http://repositorio.aee.edu.br/jspui/bitstream/aee/18122/1/JONAS.pdf. Acesso em 23 de setembro. 2021.

Souza, Elizabete. Abandono de Carrinhos em E-Commerces no Brasil. Pontifica Universidade Católica do Rio de Janeiro - PUC 2019.

TRAVER, C.; LAUDON, K. E-Commerce 2017, Global Edition. Pearson Education Limited, 2017. 
SOUZA, Felipe Lorenzeto; RAMOS, Ritler Barbosa; NAZARÉ, Tiago Bittencourt. APLICAÇÃO DO MÉTODO FRETE GRÁTIS EM UMA LOJA VIRTUAL EM CONJUNTO A ANÁLISES DE DADOS E COMPARATIVOS ATRAVÉS DO SOFTWARE POWER BI

\section{APÊNDICE I}

\begin{tabular}{|c|c|c|c|c|c|}
\hline \multicolumn{2}{|c|}{ Contagem de Gêneros } & \multicolumn{2}{|c|}{$\begin{array}{c}\text { Contagem por Estado em } \\
\text { tabela }\end{array}$} & \multicolumn{2}{|c|}{$\begin{array}{c}\text { Contagem por Estado em } \\
\text { Mapa Geográfico }\end{array}$} \\
\hline Visualizaçes & Campos & Visualizacōes & Campos & Visualizaçes & Campos \\
\hline 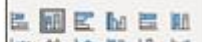 & $\rho$ pesquisar & 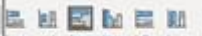 & $\rho$ pesquisar & 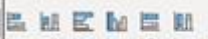 & $\rho$ Pesquisar \\
\hline 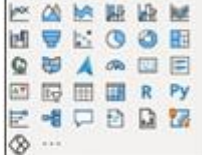 & 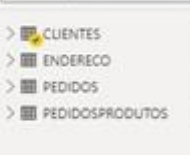 & 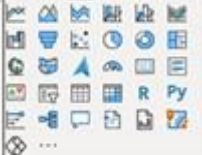 & 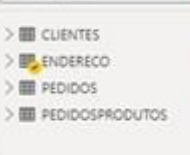 & 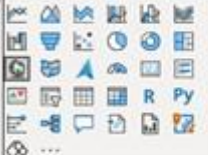 & 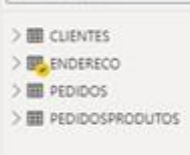 \\
\hline 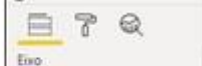 & & 르 & & E 8 & \\
\hline $\begin{array}{l}\text { fiso } \\
\text { Generes } \quad \checkmark x\end{array}$ & & $\begin{array}{ll}\text { Exao } \\
\text { Etrassot } & v x\end{array}$ & & $\begin{array}{l}\text { Locosirachio } \\
\text { Estados }\end{array}$ & \\
\hline cosences & & Logensis & & 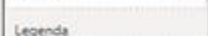 & \\
\hline 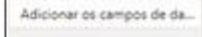 & & 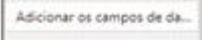 & & Adicioneres co campes de de & \\
\hline vabeen & & waberes & & Imande & \\
\hline Contagem de Generer $v X$ & & Costegem de fitasoses $v x$ & & Adicione of campor de de. & \\
\hline
\end{tabular}

\begin{tabular}{|c|c|c|c|c|c|}
\hline \multicolumn{2}{|c|}{ Contagem de Gêneros } & \multicolumn{2}{|c|}{$\begin{array}{l}\text { Contagem por Tipo } \\
\text { (Físico ou Jurídico) }\end{array}$} & \multicolumn{2}{|c|}{ Contas Criadas } \\
\hline Visualizacoes $>$ & Campos & Visualizacóes & Campos & Visualizacoes & Campes \\
\hline E国区以的 & $\rho$ Pesquisar & E w & $\rho$ Pesquisar & 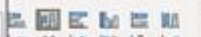 & fo perquisar \\
\hline 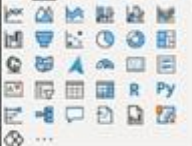 & 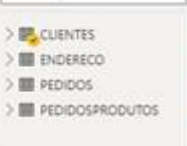 & 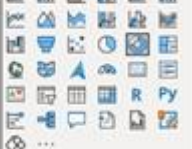 & 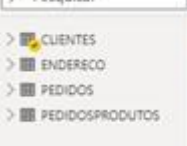 & 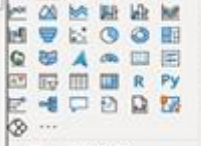 & 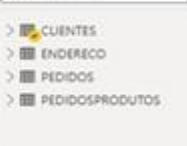 \\
\hline 亘 82 & & 血 8 & & $\frac{E}{60} 8$ & \\
\hline & & cogende & & 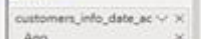 & \\
\hline Geresen & & Tos de Prestiso & & $\begin{array}{ll}A_{\infty} & x \\
M_{k} & x \\
\end{array}$ & \\
\hline Logends & & Derailes & & Logende & \\
\hline Adivener os compes de se. & & 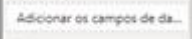 & & 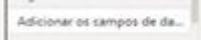 & \\
\hline valores & & vobres & & veroet & \\
\hline Contagem de Generos $\vee x$ & & Cocespem de Tso de $2 \cup x$ & & Conesgem de customer $x x$ : & \\
\hline
\end{tabular}

\begin{tabular}{|c|c|c|c|}
\hline $\begin{array}{r}\text { Contagem p } \\
\text { ou Ju }\end{array}$ & $\begin{array}{l}\text { Tipo (Físico } \\
\text { ídico) }\end{array}$ & Contas & Criadas \\
\hline Visualizacŏes & Campos & Visualizaç̄es & Campos \\
\hline 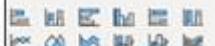 & $\rho$ Pesquisar & 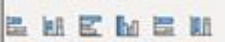 & OP pesquisar \\
\hline 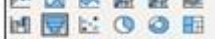 & $>$ P, Cumitrs & 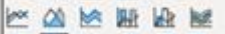 & \\
\hline$Q$ 包的回 & $>$ int Enderico & 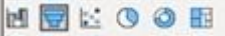 & $>$ P,CUENTES \\
\hline 四四四四 & 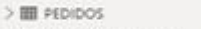 & Q ह & $>$ m ENDERECO \\
\hline 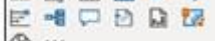 & > an PEODOSPHOOUTOS & 图回四四 $\vec{R}$ & > Im PeDidos \\
\hline$\theta \cdots$ & & 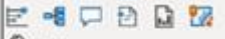 & $>$ PEDIDOSPAODUTOS \\
\hline$\underline{0} a$ & & $\otimes \cdots$ & \\
\hline 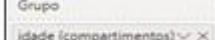 & & 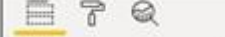 & \\
\hline 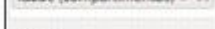 & & Ginpo & \\
\hline valores & & Customen_comocontres $v x$ & \\
\hline Contagem de idade icor $\checkmark x$ & & & \\
\hline Dicas de ferramentas & & Volores & \\
\hline Adscioneres es campos de de. & & Contagem de customen $\vee X$ & \\
\hline
\end{tabular}

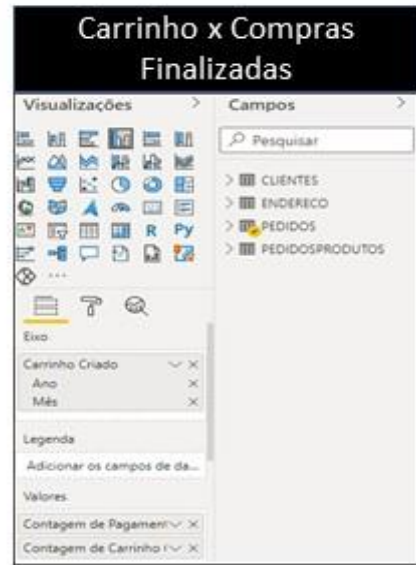

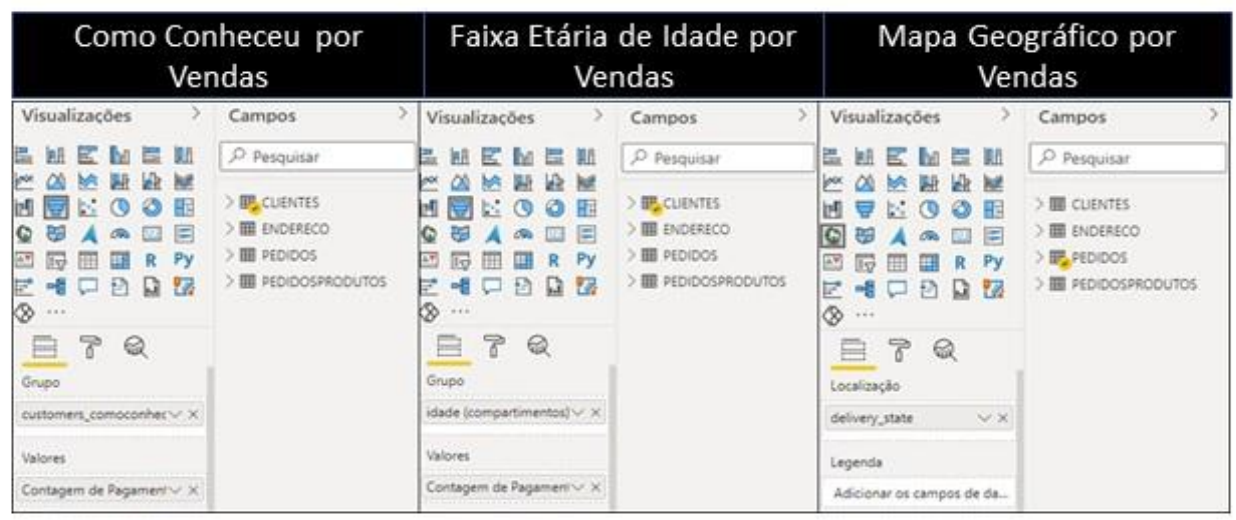

